Endocrinol. Japon. 1959, 6 (3), 153 160

\title{
THE EFFECTS OF PROLACTIN ON THE RESPIRATORY AGTIVITY OF NORMALLY LACTATING AND OF UNILATERALLY LIGATED MAMMARY GLANDS IN THE MOUSE
}

\author{
HIDEO MIZUNO AND TATEKI CHIKAMUNE \\ Department of Animal Breeding, Faculty of Agriculture, \\ University of Tokyo
}

The necessity of the suckling stimulus to the maintenance of lactation or mammary structure and its neurohormonal connection have been investigated not only by histological studies (Selye, 1934; Hooker and Williams, 1941; Williams, 1945; Benson and Folley, 1957) but also by the respiratory activity of mammary tissue slices (McNaught, 1956, 1957; Mizuno and Chikamune, 1958; Ota and Yokoyama, 1958). In our previous experiments (Mizuno and Chikamune, 1958), the forced weaning caused the abrupt fall in the respiratory activity of mouse mammary gland slices. Moreover, the fact that the non-removal of milk from the gland can be a factor of such a reduction of activity, and further the possibility that the engorgement of milk in unilaterally ligated gland might systemically inhibit the activity of even the suckled side, were shown. However, from the results of renursing experiment, it was suggested that the lactogenic and mammogenic hormone(s) which had been stored during the dislocation of the young and were liberated from the anterior pituitary by the recommenced suckling stimulus, might be effective for the maintenance or amelioration of respiratory activity of the mammary gland.

If it is tenable, the administration of prolactin, one of the most plausible factors, may stimulate the mammary respiratory function. The present experiment was conducted to determine whether such is the case.

\section{MATERIALS AND METHODS}

The Kasukabe mice which have been bred in our laboratory were used. In most cases the animals were in the 2nd lactation. All litters were made to 6 per mother on the day of delivery ( 0 day of lactation). Litters were weighed daily to assess the lactational performance of the mother and the mothers were also weighed daily.

Prolactin solution dissolved in its diluent (0.5\% phenol) and containing $200 \mathrm{i}$. u. prolactin per $\mathrm{ml}$ was administered subcutaneously into 3 groups of animals as follows.

Group 1. Prolactin was injected in doses of $20 \mathrm{i}$ u. 3 times every $8 \mathrm{hrs}$. during 24 hrs. into the normally lactating mice on the 14th day of lactation.

Group 2. On the 14th day of lactation, the mice in this group were undergone the unilateral ligature of inguinal nipples and their pups were allowed to suckle continuously. Soon after ligature prolactin was injected in the same doses and manners as Group 1.

Received for publication May 30, 1959. 
Group 3. The mice in this group were injected with prolactin of $20 \mathrm{i}$. u. once daily for 6 days, beginning from the 14 th day of lactation when the unilateral ligature technique was undertaken as Group 2.

Prolactin preparation was "Luteotrophin Squibb" supplied by E. R. Squibb \& Sons.

The animals were killed $8 \mathrm{hrs}$. after the last injection of prolactin (i.e. on the 15th day of lactation) in Group 1 and 2, and on the 20th day of lactation in Group 3.

The oxygen consumption and R. Q. of the mammary tissue slices from these animals were measured manometrically as described previously (Mizuno and Chikamune, 1958). The incubation was carried out for $\mathrm{I} \mathrm{hr}$. at $37.5^{\circ} \mathrm{C}$ in the Krebs-Ringer phosphate buffer solution $(\mathrm{pH} 7.4)$ added with $0.3 \%$ glucose. The gas phase was $100 \%$ oxygen. The oxygen consumption was expressed as $\mu \mathrm{l}$ for $1 \mathrm{hr}$. on the basis of $100 \mathrm{mg}$ initial wet weight.

Sections were also prepared for the histological inspection in the same way as the previous experiment.

\section{RESULTS}

Respiratory aclivity (Table 1)

Table 1. Effects of prolactin* on the respiratory activity of the mouse mammary gland slice

\begin{tabular}{|c|c|c|c|c|c|c|}
\hline & $\begin{array}{l}\text { No. of } \\
\text { mice }\end{array}$ & $\begin{array}{l}\text { Body weight } \\
\text { at sacrifice } \\
(\mathrm{g})\end{array}$ & $\begin{array}{l}\text { Unligated } \\
-0_{2} \mu \mathrm{l} / 100 \mathrm{mg} \\
\text { wet wt. } / \mathrm{hr} .\end{array}$ & $\begin{array}{l}\text { d gland } \\
\text { R. Q. }\end{array}$ & $\begin{array}{r}\text { Ligated } \\
-0_{2} \mu \mathrm{l} / 100 \mathrm{mg} \\
\text { wet wt. } / \mathrm{hr}\end{array}$ & $\begin{array}{l}\text { d gland } \\
\text { ing } \quad \text { R. } Q .\end{array}$ \\
\hline Normally lactating** & 6 & $31.3 \pm 1.0$ & $119.2 \pm 10.8$ & $1.64 \pm 0.08$ & - & - \\
\hline$"+$ prolactin (Group 1) & 8 & $28.2 \pm 1.5$ & $81.9 \pm 10.7$ & $1.27 \pm 0.12$ & - & - \\
\hline One day after ligation** & * 10 & $29.4 \pm 1.1$ & $76.3 \pm 9.4$ & $1.17 \pm 0.08$ & $40.4 \pm 3.0$ & $0.86 \pm 0.09$ \\
\hline "+prolactin (Group 2) & 17 & $29.5 \pm 0.6$ & $94.4 \pm 11.4$ & $1.46 \pm 0.07$ & $41.8 \pm 2.5$ & $1.00 \pm 0.03$ \\
\hline Six days after ligation** & 7 & $24.9 \pm 1.3$ & $133.9 \pm 11.0$ & $1.48 \pm 0.09$ & $69.1 \pm 2.9$ & $0.66 \pm 0.11$ \\
\hline "+prolactin (Group 3) & 4 & $29.8 \pm 0.7$ & $116.6 \pm 6.8$ & $1.49 \pm 0.03$ & $54.5 \pm 2.9$ & $0.77 \pm 0.11$ \\
\hline Renursed group** & 4 & $29.8 \pm 0.7$ & $151.2 \pm 12.3$ & $1.54 \pm 0.10$ & - & - \\
\hline
\end{tabular}

The values of respiratory activity of non-injected controls were cited from the previous results.

The oxygen consumption and R. Q. of the mammary glands from the animals in Group 1 were significantly lower than those of non-injected normally lactating controls on the 14 th day of lactation $(\mathrm{P}<0.05$ both in oxygen consumption and R. Q.).

In Group 2, the oxygen consumption of unligated gland was apparently higher than that of unilaterally ligated control without prolactin injection but not statistically significant. However, in 5 of 17 animals receiving prolactin the oxygen consumption of unligated gland markedly rose up to the same extent to those of renursed animals. On the other hand, the oxygen consumption in ligated side was not altered by prolactin injection. The R. Q. was significantly elevated by 
prolactin injection in unligated side $(\mathrm{p}<0.05)$, whereas in ligated side it was not affected.

In Group 3, no significant difference in the respiratory activities was observed between this group and the non-injected controls which were ligated unilaterally for 6 days, excepting that the oxygen consumption in ligated side was significantly lower in the prolactin injected group than in the non-injected control.

Body weight

Body weights of mothers remained fairly constant from their deliveries to the time of sacrifice.

Body weights of litters increased linearly from the time of their birth until the 14th day of lactation, when various experimental treatments were undertaken in each group, so that thereafter the growth curve manifested their characteristics according to each treatment.

When pups were allowed to suckle normally, their body weights continued to increase steadily day by day till the 20th day of lactation.

The body weights of pups decreased greatly when they were removed from their mothers involuntarily on the 14th day of lactation and starved for one day, but they recovered if they were renursed for one day. This is the case with the animals which were undergone unilateral ligature prior to renursing.

Further it is noticeable that pups did neither gain nor lose their weights on the next day, when their mothers were undergone unilateral ligation on the 14th day of lactation. But two days after ligature they began to gain their weights and thereafter steadily continued to increase.

Such curves of pups' body weights were not markedly altered by administration of prolactin to their mothers in doses and manners described above.

Histological observation (Plate 1)

Sections from animals receiving prolactin showed considerably different findings from those of non-treated controls.

Sections from mice in Group 1 showed the alveolar cells with more abundant cytoplasm, and smaller and more deeply stained nuclei than the intact normal control. Small globules of fat were seen as vacuoles in the cytoplasm of the epithelial cells (Fig. 1).

In Group 2, sections from unligated glands of animals, in which the values of oxygen consumption and R.Q. were fairly high, showed the alveolar cells which were hypertrophic and had a compact deeply stained nucleus in each. Secretion with small globules of fat filled the alveolar lumen, so that cytoplasm could not clearly be distinguished from secretion (Fig. 3). In the gland of ligated side, cells from cuboidal to flattened shape with small nuclei and larger fat globules were sustained in secretion in the alveolar lumen (Fig. 4). On the other hand, sections from unligated glands of animals which showed lower respiratory activity had similar findings to that described just above. However, alveolar cells in such animals contained somewhat larger fat globules (Fig. 5). And a ligated gland had also degenerative cells swollen with fat globules (Fig. 6).

Sections from unligated glands of animals in Group 3 (Fig. 7) showed similar pictures to those of animals which exhibited higher respiratory activity as mentioned above, while ligated glands (Fig. 8) showed the involuted appearances 
similar to the glands ligated for 6 days without prolactin treatment.

Finally, sections from the renursed group showed the picture that alveolar cells were hypertrophic and secretion with small fat globules was observed in lumen (Fig. 2). This picture was comparable to that of prolactin treated unligated gland in Group 2 which showed higher respiratory activity (Fig. 3).

\section{DISCUSSION}

In order to ameliorate or maintain the respiratory activity, prolactin was administered to normally lactating animals and animals in which unilateral nipples were ligated. In unligated glands of unilaterally ligated and prolactin injected group the oxygen consumption did not significantly increase, whereas $R$. Q. rose up close to the value of renursed group. But as mentioned above in several animals of this group, values of both oxygen consumption and R. Q. were elevated markedly to the similar extent to those of renursed group, and it was the case with histological results. Therefore, the explanation suggested by the renursing experiment in the previous report seemed to be supported by the experimental evidence.

However it should be discussed that prolactin did not stimulate but conversely suppressed the respiratory activity when it was injected into normally lactating animals. This might be explainable as follows; there are certain optimum dose levels for stimulating the function according to the condition of mammary glands, accordingly the dosage adopted in the present experiment might have been excessive for the normally functioning gland. And there are individual variations in the degree of degenerative change in unligated gland evoked by the engorgement of milk following unilateral ligature, so that if the dose is optimum it might stimulate, whereas if it is excessive or less it might lower or could not ameliorate the respiratory activity. Thus, such interpretation could account for the results obtained from the unilateral ligature group.

As to the effect of prolactin administered for 6 days, it did not significantly alter the respiratory activities both in the unligated and ligated glands. However, histological observation showed the definitely different picture from that of the prolactin untreated control on the unligated side. Therefore, it is obvious that prolactin has some influence on the mammary structure or function, although no apparent change was observed manometrically. On the other hand, prolactin could not prevent the involutional change on the ligated side. This is in contrast to the results of Selye (1934), Hooker and Williams (1941), Williams (1945), and Benson and Folley (1957), who showed that unilateral suckling stimuli or prolactin administration could retard the involution following the weaning. Here again, the dosage of hormone is of course a problem. Furthermore, it may be possible that there are some differences in the rapidity of retrogressive change, according to the species or the stage of lactation.

Nevertheless, such interpretation is yet impossible to explain sufficiently the complicate effects of prolactin in connection with the effect of suckling stimulus on the mammary gland. It has also been shown that the other hormone than prolactin, such as ACTH, is secreted reflectively from the anterior pituitary 
by suckling stimulus. Indeed, more recently Johnson and Meites (1958) showed that cortisone could retard the involution of rat mammary gland after weaning. Therefore further study should be carried out to enlighten the effect of prolactin in combination with other hormones on the maintenance of alveolar structure.

It has been shown that R. Q. above unity during lactation reflects on the true fat synthesis and that respiratory activities increase gradually as lactation advances to the peak, but significant correlation of $R$. Q. with the fat synthesis rate or of respiration with lactational performance has never been investigated, so far. From the present results, it seems that prolactin exerts some influence qualitatively on the metabolic or synthetic process, because R. Q. was always above unity, even if it was altered, but the values of oxygen consumption did not always change in parallel with R. Q. by prolactin. And further this may also be suggested from the result of pups' weight. In spite of alterations of respiratory activities discussed above, littler's weight was not so altered by prolactin treatment. Then, it may be possible to say that the effect of prolactin on the synthetic activity is not quantitative but qualitative, provided that the change of litter's body weight was reflected on the mother's milk yield in such a short period as $24 \mathrm{hrs}$. This fact is in agreement with the previous view that pure prolactin alone has no galactopoietic effect.

The metabolism of some oxidative enzymes and oxidation of substrate of mammary tissue have been investigated during the normal lactation cycle, but few studies were reported about the effect of experimentally administered prolactin, in this respect. Read and Moore (1958) studied the effects of intramammary injections of prolactin upon the accumulation of coenzyme $\mathrm{A}$ in lactating guinea pigs. Williams and Turner (1956) reported that the great majority of intraductally injected $I^{131}$-labeled prolactin became associated with the particles in cytoplasm, and discussed the effect of prolactin on the biochemical changes of the cells during the initiation and maintenance of lactation. Therefore, more precise interpretation about the effect of prolactin on the metabolism of mammary gland should await further investigation in relation to cellular structure.

In this experiment, treatments were carried out on the 14th day, when lactational function of the mouse reached the peak, judging from RNA content as reported by Chikamune and Mizuno (1958). It will be interesting to investigate further the effects of engorgement of milk and suckling stimulus involving the hormonal treatment, such as prolactin and/or other hormones, on the maintenance of mammary structure and function, in connection with the stage of lactation as well as the weaning period.

\section{SUMMARY}

Prolactin was injected to the normally lactating and unilaterally ligated mice in order to ameliorate or maintain the respiratory activity of the mammary gland. From the results of the histological observation and litter's growth curve in addition to the respiratory activities, it was suggested that prolactin might exert some influence on metabolic or synthetic process, qualitatively but not quantitatively. And it was discussed that there might exist a certain optimum dose 
according to the condition of mammary gland for prolactin to exert stimulatory effect on the mammary respiratory activity. However, prolactin, in adopted doses, did not prevent the involution occurring in the ligated gland six days after unilateral ligature. From these results it may be possible to conclude that the removal of milk might be a limiting factor, and further, prolactin may be effective for maintaining the mammary gland in the functioning state, although the dosage of hormone in connection with the stage of lactation is an important factor.

\section{ACKNOWLEDGEMENTS}

The authors wish to express their hearty thanks to Prof. M. Naito for his kindness in reading the original manuscript and also to Dr. R. B. Edwards, E. R. Squibb \& Sons, for his kind donation of prolactin preparation.

\section{REFERENCES}

Benson, G. K. and S. J. Folley (1957). J. Endocrinol. 16, 189.

Chikamune, T. and H. Mizuno (1958). Jap. J. Zootech. Sci. 29, Suppl. 13. (In Japanese)

Hooker, C. W. and W. L. Williams (1941). Endocrinology 28, 42.

Johnson, R. M. and J. Meites (1958). Endocrinology 63, 290.

McNaught, M. L. (1956). Annual Report of National Institute for Research in Dairying, England. p. 59 .

McNaught, M. L. (1957). Annual Report of National Institute for Research in Dairying, England. p. 58.

Mizuno, H. and T. Chikamune (1958). Endocrinol. Japon. 5, 265.

Ota, K. and A. Yokoyama (1958). Nature 182, 1509.

Read, M. S. and R. O. Moore (1958). Arch. Biochem. Biophys. 77, 1.

Selye, H. (1934). Am. J. Physiol. 107, 535.

Williams, W. L. (1945). Anat. Record. 93, 171.

Williams, W. F. and C. W. Turner (1956). Mo. Agric. Exp. Res. Sta. Bull. No. 598. 
Fig. 1. Section from inguinal mammary gland of normally lactating mouse receiving prolactin in doses of 20 i.u. three times during $24 \mathrm{hrs}$, from the 14 th day of lactation (Group 1).

Fig. 2. Section from inguinal mammary gland of mouse on the next day after renursing was recommenced on the following day to removal of young on the 14th day of lactation.

Fig. 3. Section from unligated inguinal mammary gland of mouse receiving unilateral ligature and prolactin in doses of 20 i.u. three times during $24 \mathrm{hrs}$. from the 14th day and showing the fairly high respiratory activity (Group 2).

Fig. 4. Section from ligated inguinal mammary gland of mouse receiving unilateral ligature and prolactin in doses of 20 i.u. three times during $24 \mathrm{hrs}$. from the 14 th day and showing the fairly high respiratory activity (Group 2).

Fig. 5. Section from unligated inguinal mammary gland of mouse receiving unilateral ligature and prolactin in doses of 20 i.u. ihree times during $24 \mathrm{hrs}$. from the 14th day and showing the lower respiratory activity (Group 2).

Fig. 6. Section from ligated inguinal mammary gland of mouse receiving unilateral ligature and prolactin in doses of 20 i.u. three times during $24 \mathrm{hrs}$. from the 14th day and showing the lower respiratory activity (Group 2).

Fig. 7. Section from unligated inguinal mammary gland of mouse receiving unilateral ligature and prolactin in dose of 20 i.u. once daily for six days from the 14th day of lactation (Group 3).

Fig. 8. Section from ligated inguinal mammary gland of mouse receiving unilateral ligature and prolactin in dose of 20 i.u. once daily for six days from the 14th day of lactation (Group 3). 

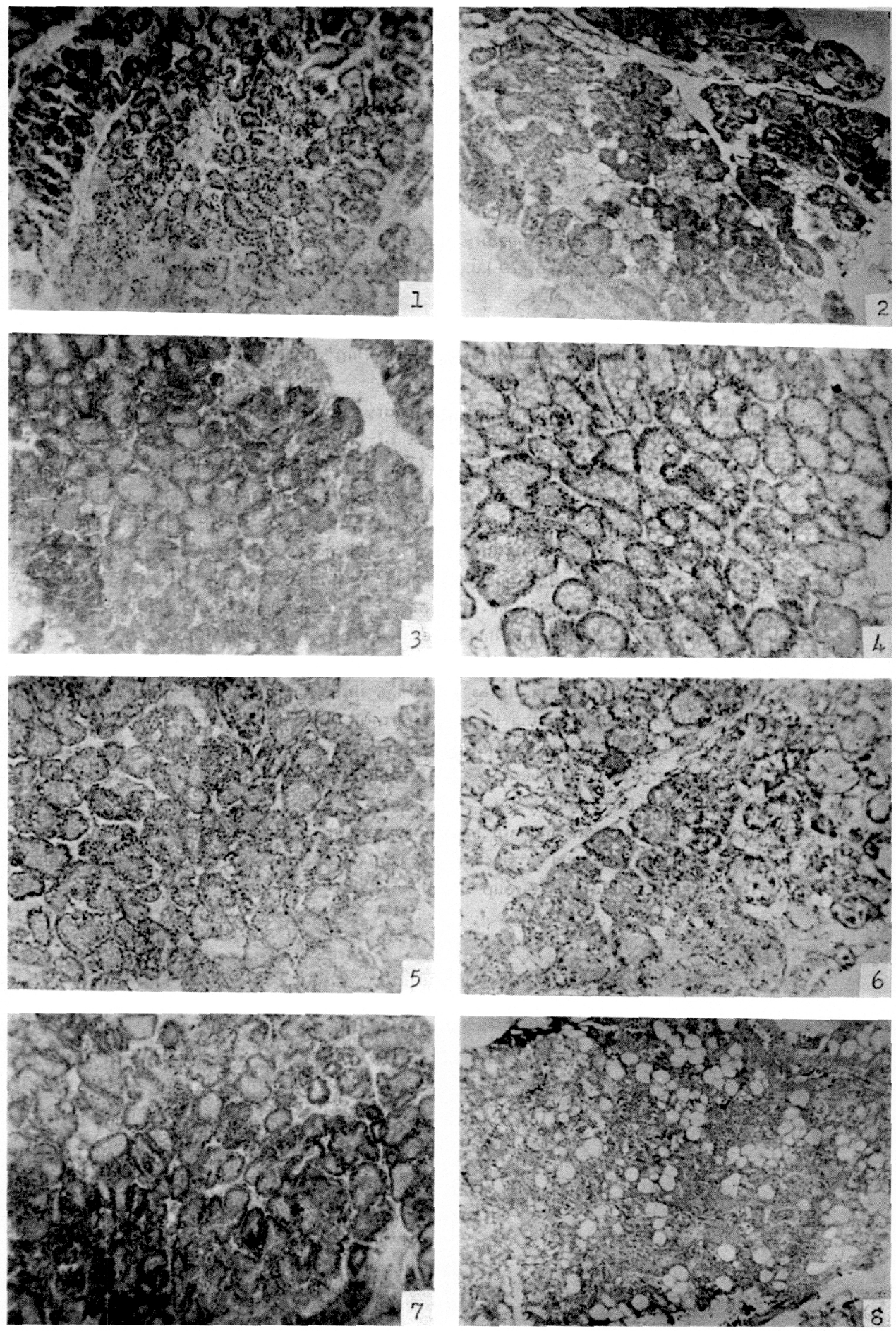